\title{
Assessment of antenatal care of third trimester pregnant women attending in antenatal clinic at Mohammadpur Fertility Services \& Training Centre of Dhaka, Bangladesh
}

\begin{abstract}
In Bangladesh 37\% of pregnant women are taking four step of ANC treatment. The main purpose of this study was to identify the factor associated with ANC checkup. A hospital based cross sectional study at Mohammadpur Fertility Services and Training Center (MFSTC), Mohammadpur, Dhaka, Bangladesh. This cross sectional study was conveyed 100 pregnant women who visited the Mohammadpur Fertility Services and Training Center for taking antenatal checkup. Total 100 pregnant women's data was collected in which $12 \%$, 2nd trimester and $88 \%$, 3rd trimester of pregnancy. According to the amount $3 \mathrm{rd}$ trimester of pregnant women came this hospital for antenatal checkup. Demographic data and information on age height, weight, religion, educational qualification, birth control method, health problem, blood donor, physical test, tetanus vaccine, family income level, and economical effect were collected from the patient by using a questionnaire.
\end{abstract}

A good number of the pregnant women normally eaten balanced food. Some of the patients maintain the proper antenatal instruction and take more seasonal fruits and vegetable, egg, milk, fish to satisfy their nutrients for maternal health care period.
Volume 7 Issue I - 202 I

\author{
Hossain B,Akhter F,AC Apou, Rubaya \\ Ahmed, N Uddin \\ Department of Nutrition and Food Engineering, Faculty of Allied \\ Health Sciences, Bangladesh
}

\begin{abstract}
Correspondence: Bellal Hossain, Department of Nutrition and Food Engineering, Daffodil International University, Dhaka, Bangladesh, Tel 00880I680378493,

Email drbellal@daffodilvarsity.edu.bd
\end{abstract}

Received: May 22, 2020 | Published: February 26, 2021

Keywords: pregnancy, antenatal care center, factors , MFSTC, Bangladesh

Abbreviations: AVC, antenatal care center; MFSTC, Mohammadpur fertility services and training center; MR, Maternity research

\section{Introduction}

Antenatal care means "care before birth", includes education, counseling, treatment, monitoring, and improving the health condition of the mother and fetus. In this trimester, pregnant mother should be under the observation of health care, medicine, nutrition, checkup follow up for birth a healthy child. World Health Organization recommends at least four times antenatal visit in hospital to keep body fitness during the period but half of the pregnant women follow the recommends. WHO estimates that more than 529,000 women die every year from complication of pregnancy. ${ }^{1}$ It is comparatively high in developing countries than developed countries. So that the importance of women knowledge is very much required.

Antenatal care (AVC) is a critical feature during pregnancy period also help to the survive of women and newborns .At past many of women died during pregnancy period due to lacking of proper knowledge .Maternal mortality has been decreased in Bangladesh day to day in the under developed areas as compared to advance than rural area. At present, Bangladesh Government takes many essential steps for antenatal care so that women are very aware about their special care during pregnancy period. Most of the pregnant mother suffer from Iron deficiency anemia, lack of hemoglobin, majority of them in Bangladesh start their gestational life with anemia. In a study ${ }^{2}$ shown that under developed areas pregnant women were well nourished than rural pregnant women. In addition, an observation from this study about $86 \%$ women attending at least four ANC visit with the targets of sustainable development goal to deceased the maternal mortality. ${ }^{2}$
WHO pointed that the second half of the 20th century, international awareness grew of the dimensions of the tragedy of maternal mortality and developing countries governments collaborated with technical assistance and donor agencies to ensure the pregnant women maternity care. ${ }^{3}$ However, providing access for all pregnant women to antenatal care during the short period of labor and delivery is logistically and operationally a much more complex endeavor than making services available during the much longer - and less unpredictable antenatal period. There is the commitment that focus of antenatal care interventions should be on improving maternal health, this being both an end in itself and necessary for improving the health and survival of infants. Today we have better evidence about what works and what does not work to reduce maternal mortality, and the role that antenatal care can play. For the improvement of maternal health care, barriers that limit access to quality maternal health services should be identified and focused at all levels of the health care management. Health wellbeing is an important tools to illiterate women to be train of their health status and the importance of appropriate ANC. Very few studied were carried out in Bangladesh about this aspect of maternal health and hence data in this regard is scarcely available. ${ }^{2}$ Maternal mortality is on an average 18 times higher in developed countries compared to developing countries. ${ }^{4}$ In addition to the number of deaths each year, over 50 million women suffer from maternal morbidity due to acute complications from pregnancy. ${ }^{5}$

\section{Methods and materials}

\section{Study design and settings}

A maternal hospital -based, cross-sectional survey was conducted in Mohammadpur Fertility Services \& Training Centre of Dhaka in Bangladesh in 2019. In this center, MR services in Bangladesh was first initiated, nurtured and attained its maturity. Maternity research 
(MR) is the most important aspect of women services ensuring their fulfilment of right toward reproductive health. Out of all clients who visit this center each year, about $80 \%$ are from the lower and middle income bracket which is an indication of its popularity and its good performance, quality counselling, record keeping and follow-up services provided to the clients. Due to the great need and demand of the locality, The Government of the People's Republic of Bangladesh upgraded this MFSTC to 100 bedded Mother and Child Health Hospital after approval of the institutional ethical committee. All married women in the age group of 18-38 years who were pregnant at the time of interview.

\section{Study population, sample size and sampling}

Married women with a recent history of birth (within the 12-month period preceding the survey) who were permanent residents near to the locality of MR hospital were eligible to be included in the study. All eligible respondents were included from the selected AVC Visit record sheet. A total of 100 women with a recent history of birth were interviewed. In this study, 100 antenatal visitors as sample (AVC) was selected from patents attendance sheet of the hospital. ${ }^{6-17}$

\section{Data collection}

The cross sectional survey was conducted in March - October 2019. All respondent patents in the selected list were enumerated and recorded. Then all women with a recent history of birth were screened and identified from the listed sheet of Hospital AVC visit center. In the second stage, interviewer-administered structured questionnaires were used for interviewing all eligible women. The questions were adapted from the tools used in Bangladesh Maternal Mortality Survey (BMMS), Multiple Indicator Cluster Survey (MICS) and other relevant studies. ${ }^{18-21}$ The questionnaire started with questions regarding personal and socioeconomic information such as age, education level, marital status and employment status followed by questions related to utilization of routine and emergency obstetric care, the coverage and content of ANC contacts attended and knowledge related to pregnancy and birth. For quality assurance, the questionnaire was pre-tested in non-selected visitors of the working MR Center. Experienced facilitators, trainers and hospital supervisors trained the data collectors.

\section{Data analysis}

Age and education level of the women and their husbands were transformed into categorical variables. Due to small sample numbers, all other religions were grouped into different category. We used the standard steps of principal component analysis to generate the socioeconomic indices of the listed ANC Visitors that were interviewed, based on which the wealth quintile was generated..$^{21-23}$ Initially, the content of ANC contacts was analyzed considering individual women as the unit of analysis. Specific content of ANC contacts were reported using descriptive statistics stratified by frequency and timing i.e., content received during the first ANC contact, content received in the first, second and third trimesters and content received in all trimesters.

\section{Results}

From the total 100 participants, pregnancy rate was $36.8 \%$ of 21 -weeks ; $63.1 \%$ of 25 -weeks ; $25 \%$ of 30 -weeks, $45.4 \%$ of 34 -weeks , and $29.5 \%$ of 38 - weeks . Data shows that $12 \%$ were $2^{\text {nd }}$ trimesters and $88 \%$ were $3^{\text {rd }}$ trimester of pregnancy observed. In total 100 pregnant mother attended ANC at MFSTC during this study, where each of them responded in same questionnaire. Among the study, majority of the pregnant women aged in between $21-25(50 \%)$. The religion of pregnant women $106.8 \%$ Muslim, 5.68\% Hindu, and $1.13 \%$ Christian respectively. The average height of the patent was
$52.2 \%$ from the range between $151-160 \mathrm{~cm}$. The range of weight $56.8 \%$ of pregnant mother in between $61-70 \mathrm{~kg}$ was also investigated from the data of this study (Tables 1\&2).

Table I Socio-economic and demographic history of $2^{\text {nd }}$ and $3^{\text {rd }}$ trimesters of pregnant mother

\begin{tabular}{|c|c|c|c|}
\hline Variable & Category & Frequency & Percent \\
\hline \multirow[t]{5}{*}{ Age } & $18-20$ & 14 & $15.90 \%$ \\
\hline & $21-25$ & 44 & $50.00 \%$ \\
\hline & $26-25$ & 29 & $32.90 \%$ \\
\hline & $31-35$ & 10 & $11.30 \%$ \\
\hline & $36-40$ & 3 & $3.40 \%$ \\
\hline \multirow[t]{4}{*}{ Weight } & $40-50$ & 11 & $12.50 \%$ \\
\hline & $51-60$ & 34 & $38.60 \%$ \\
\hline & $61-70$ & 50 & $56.80 \%$ \\
\hline & $>70$ & 5 & $5.60 \%$ \\
\hline \multirow[t]{4}{*}{ Height } & $142-150 \mathrm{~cm}$ & 16 & $18.18 \%$ \\
\hline & $151-155 \mathrm{~cm}$ & 46 & $52.20 \%$ \\
\hline & $156-160 \mathrm{~cm}$ & 34 & $38.60 \%$ \\
\hline & $>160 \mathrm{~cm}$ & 4 & $4.50 \%$ \\
\hline \multirow[t]{3}{*}{ Religion } & Muslim & 94 & $106.80 \%$ \\
\hline & Hindu & 5 & $5.58 \%$ \\
\hline & Christian & 1 & $1.13 \%$ \\
\hline
\end{tabular}

Table 2 Economical and economical background among pregnant women

\begin{tabular}{llll}
\hline Variable & Category & Frequency & Percentage \\
\hline $\begin{array}{llll}\text { Educational } \\
\text { Qualification }\end{array}$ & No Education & 6 & $6.81 \%$ \\
& Primary level & 41 & $46.50 \%$ \\
& Six to Nine class & 30 & $34.00 \%$ \\
& Secondary & 10 & $11.30 \%$ \\
& Higher Secondary & 6 & $6.80 \%$ \\
& Above Secondary & 7 & $7.90 \%$ \\
$\begin{array}{l}\text { Occupation of } \\
\text { the sample }\end{array}$ & Housewife & 78 & $88.60 \%$ \\
& Job Holder & 7 & $7.90 \%$ \\
& Student & 2 & $2.27 \%$ \\
& Worker & 13 & $14.70 \%$ \\
$\begin{array}{l}\text { Husbands } \\
\text { Occupation }\end{array}$ & Business & 5 & $5.60 \%$ \\
& Job Holder & 36 & $40.90 \%$ \\
& Worker & 59 & $67.04 \%$ \\
$\begin{array}{l}\text { Pamily Income } \\
\text { (Tk.) }\end{array}$ & 10,000 - 20,000 & 60 & $68.10 \%$ \\
& $21,000-30,000$ & 27 & $30.60 \%$ \\
\hline & 130000 & & $14.70 \%$ \\
\hline
\end{tabular}


Among the selected sample under the study as per design, majority of the pregnant women's' educational background $46.5 \%$ primary level and $34.0 \%$ six to nine class, $11.3 \%$ secondary level , and $6.8 \%$ higher secondary level ; 88.6\% housewife, and $14.7 \%$ worker. Most of the cases, the patient's husband were only earning person i.e., $40.9 \%$. Job holder, $67.04 \%$ worker. The income range of their husbands were $68.1 \%$ in between Tk. 10,000- Tk.20, 000 respectively. Table 3 shows that the majority respondent were new mother $(61.3 \%)$, miscarriage (1\%), gestational age3 Trimester (88\%), and Implanon used (76.1\%) for birth control method respectively.

Table 3 Reproductive history of the literate pregnant women attended at ANC , MFSTC

\begin{tabular}{llll}
\hline Variable & Category & Frequency & Percentage \\
\hline $\begin{array}{l}\text { Number of } \\
\text { Children }\end{array}$ & Second Child & 35 & $39.70 \%$ \\
& Third or More Child & 10 & $11.30 \%$ \\
& New Mother & 54 & $61.30 \%$ \\
$\begin{array}{l}\text { Miscarriage } \\
\text { history }\end{array}$ & Miscarriage & 1 & $1.13 \%$ \\
$\begin{array}{l}\text { Gestational Age } \\
\text { Ist Trimester }\end{array}$ & 0 & $0.00 \%$ \\
& 2nd Trimester & 12 & $12 \%$ \\
& 3rd Trimester & 88 & $88 \%$ \\
$\begin{array}{l}\text { Acceptance of } \\
\text { Birth Control } \\
\text { method }\end{array}$ & Pill & 7 & $7.90 \%$ \\
& Condom & 7 & $7.90 \%$ \\
& Vaginal Ring & 4 & $13.60 \%$ \\
& Ligation & 3 & $4.50 \%$ \\
& Implanon & 67 & $7.40 \%$ \\
\hline
\end{tabular}

From the investigated data of analysis in the Table 4 shows $22.75 \%$ of pregnant women suffer from vomiting , 33.7\% lower abdominal pain, $7.9 \%$ headache , $21.5 \%$ dizziness, $6.8 \%$ loss of appetite and $14.7 \%$ of others such as low pressure, malnourished, high pressure, kidney problem, liver diseases, and diabetes.

Table 4 Type of health complications during pregnancy period

\begin{tabular}{llll}
\hline Variable & Category & Frequency & Percentage \\
\hline & $\begin{array}{l}\text { Lower abdominal } \\
\text { pain }\end{array}$ & 35 & $39.70 \%$ \\
& Headache & 7 & $7.90 \%$ \\
& Vomiting & 20 & $22.70 \%$ \\
Health & Dizziness & 19 & $21.50 \%$ \\
$\begin{array}{l}\text { Complication } \\
\end{array}$ & Loss Appetite & 6 & $6.80 \%$ \\
& Others ( Malnourish, & 13 & $14.70 \%$ \\
& Low blood pressure, & \\
& High blood pressure, & \\
& Kidney problem, Diabetes, Liver & \\
& Diseases ) & \\
\hline
\end{tabular}

From the Table 5, the data shows that the majority of pregnant mother were $79.5 \%$ ultrasonography, $20.4 \%$ urine test, and $13.6 \%$ blood test respectively. The data in the Table 6 found that $56.8 \%$ of pregnant women were normally used to intake. They habituated to intake various food like seasonal fruits, egg, milk, fish, green leafy vegetable etc., but in the other cases, $35.2 \%$ women were not eating in first pregnancy period normally. In this study, about $21.5 \%$ women liked fruits and vegetable, egg, milk, peanut, and fish, in large amount of their meal. In Table 7, data shows that $81 \%$ women had economical effect. $19.3 \%$ women had no economic effect, and $12.5 \%$ of pregnant women had little economical effect respectively. Data of the study found a total of $69.3 \%$ pregnant women completed their Tetanus Vaccination because they were careful during pregnant period, and $44.3 \%$ were not under vaccination (Tables $8 \& 9$ ).

Table 5 Types of physical test of pregnancy mother attended ANC , MFSTC

\begin{tabular}{llll}
\hline Variable & Category & Frequency & Percentage \\
\hline Physical Test & Ultrasonography & 70 & $79.50 \%$ \\
& Urine test & 18 & $20.40 \%$ \\
& Blood Test & 12 & $13.60 \%$
\end{tabular}

Table 6 Dietary habits of pregnant women attended ANC , MFSTC

\begin{tabular}{llll}
\hline Variable & Category & Frequency & Percentage \\
\hline $\begin{array}{l}\text { Dietary } \\
\text { History }\end{array}$ & Normal Eaten & 50 & $56.80 \%$ \\
& No Taste for Eating & 31 & $35.20 \%$ \\
& $\begin{array}{l}\text { Increase amount of } \\
\text { Nutrient rich Meal }\end{array}$ & 19 & $21.50 \%$
\end{tabular}

( Like Fruits,Vegetable, Meat Fish, Egg etc.,)

Table 7 Economical Effect of Pregnant mother

\begin{tabular}{llll}
\hline Variable & Category & Frequency & Percentage \\
\hline Economical Effect & Yes & 72 & $81.81 \%$ \\
& No & 17 & $19.30 \%$ \\
& Little & 11 & $12.50 \%$
\end{tabular}

Table 8 Tetanus vaccination of pregnant women

\begin{tabular}{llll}
\hline Variable & Category & Frequency & Percentage \\
\hline Tetanus Vaccination & Complete & $61 \%$ & $69.30 \%$ \\
& Incomplete & $39 \%$ & $44.30 \%$
\end{tabular}

Table 9 Status of blood donor of pregnant women regnant women

\begin{tabular}{llll}
\hline Variable & Category & Frequency & Percentage \\
\hline & Yes & 36 & $40.90 \%$ \\
$\begin{array}{c}\text { Status of Blood } \\
\text { Donor collection }\end{array}$ & No & 64 & $72.70 \%$ \\
\hline
\end{tabular}

In this survey, $40.9 \%$ pregnant women were completed blood Collection sources and $72.7 \%$ did not arranged.

In this survey about $43.1 \%$ of pregnant women wanted to Caesarean delivery because for some complication like first issues. If the height of foetus $>145 \mathrm{~cm}$ then a fewer tendency to normal delivery and $70.4 \%$ women wanted to normal delivery was found in Table 10 . Data from the Table 11 , about $62.5 \%$ of pregnant women were visited at 
MFSTC for good services of hospital management system and $13.6 \%$ were attended due to economic benefit, provided antenatal checkup. In addition, 3.40\% samples visited at ANC because of nearest local support.

Table 10 Types of maternal delivery expectation of pregnant women maternal delivery expectation of pregnant

\begin{tabular}{llll}
\hline Variable & Category & Frequency & Percentage \\
\hline Typed of Delivery & Caesarean & $38 \%$ & $43.10 \%$ \\
& Normal & $62 \%$ & $70.40 \%$
\end{tabular}

Table I I Base line data for facilities of the MFRCT Hospital for ANC checkup

\begin{tabular}{llll} 
Variable & Category & Frequency & Percentage \\
\hline $\begin{array}{l}\text { Base line input of } \\
\text { ANCVisit }\end{array}$ & For good service & 55 & $62.50 \%$ \\
& Financial reason & 12 & $13.60 \%$ \\
& Near at home & 3 & $3.40 \%$ \\
& $\begin{array}{l}\text { Both good service } \\
\text { and financial reason }\end{array}$ & 30 & $34.00 \%$ \\
\hline
\end{tabular}

In this survey, about $75 \%$ women desired for delivery at hospital cabin, $20.4 \%$ at other hospital and $18.1 \%$ did not decided their delivery location (Table 12).

Table I 2 Data of delivery location of the patents

\begin{tabular}{llll}
\hline Variable & Category & Frequency & Percentage \\
\hline $\begin{array}{l}\text { Delivery } \\
\text { location }\end{array}$ & MFSTC Hospital & 66 & $75 \%$ \\
& Another Hospital & 18 & $20.40 \%$ \\
& No Decision & 16 & $18.10 \%$ \\
\hline
\end{tabular}

\section{Discussion}

The study suggests applying an integrated conceptual framework to ascertain the extent to which the attendance at ANC clinics may be attributed to individual determinants among women from different pregnant women or to the quality of service delivery of the government antenatal health care service centers. This is consistent with our findings, in which individual determinants accounted for $50 \%$ of the systematic explained variance compared to $62.5 \%$ of the variance explained by the quality of ANC visitors' record of hospital good services. This implies that the variations in the use of ANC facilities were mainly attributable to the quality of good service as trained by pregnant women at healthcare facilities of MFRTC. The study is identified the factors associated with ANC among $2^{\text {nd }}$ and $3^{\text {rd }}$ trimester pregnant women attending in the Mohammadpur fertility Services and Training Center, Mohammadpur, Dhaka. From this report it has been found $88 \%$ of pregnant women were $3^{\text {rd }}$ trimester came to the MFSTC for antenatal checkup. Total 100 data collected from different aged pregnant mother from $2^{\text {nd }}$ and $3^{\text {rd }}$ trimester of pregnancy period. Among them $12 \% 2^{\text {nd }}$ trimester and $88 \% 3^{\text {rd }}$ trimester pregnant women. A good number of pregnant women were $3^{\text {rd }}$ trimester from the studied data to received antenatal treatment from MFSTC. Less than 30 years of old women came to this hospital, having weight of pregnant women was $61-70 \mathrm{kgs}(56.8 \%)$ and height $151-155 \mathrm{~cm}(52.2 \%)$ respectively. Particularly, our findings illustrate that the increase in the pregnant woman's level of education $(46.5 \%$, primary) is a significant motivator for increasing the likelihood of
ANC visit. This concurs with other studies demonstrating that the low level of a woman's education is associated with infrequent and no ANC, as well as delay in accessing medical help. ${ }^{21}$ It makes will force that educated women are more likely to receive the benefits of ANC facilities for health and children's well-being. Higher education may also promote patient's ability to increase visit to health staff exchanges their heath obstacles. In this report, pregnant women were housewife and they are completely depends on their husband income. Average income level did not adequate to provide proper amount of nutritional food during pregnancy period. They were careful for the tetanus vaccination and most of the women accepted Implant method for birth control due to safe and easiest method. Some women accepted the non-permanent method like pill, condom etc., and a few women accepted the permanent birth control method like ligations as per hospital management instructions. In the study, during their pregnancy period, they increased their balanced diet in every day for folic acid, phosphorus , iron, iodine, zinc, biotin , thiamin, vitamin $\mathrm{B}_{12}$, and riboflavin from green leafy vegetables, fruits, fish , meat, egg, milk . Among pregnant mother under this study group, were physical issues like vomiting, headache, lower abdominal pain, loss apatite etc. Most of the patient wanted delivery in this hospital for availing all facilities like food management, vaccinations, ultrasonography from $1^{\text {st }}$ trimester to 3 rd trimester and support for special health care and also antenatal care for pregnancy period. Most of the women accepted Implant method for birth control due to safe and easiest method. Some women accepted the non-permanent method like pill, condom etc., and a few women accepted the permanent birth control method like ligations as per hospital management instructions. In the study, during their pregnancy period, they increased their balanced diet in every day for folic acid, phosphorus, iron, iodine, zinc, biotin, thiamin, vitamin $\mathrm{B}_{12}$, and riboflavin from green leafy vegetables, fruits , fish , meat, egg, milk . Among pregnant mother under this study group, were physical issues like vomiting, headache, lower abdominal pain, loss apatite etc. Most of the patient wanted delivery in this hospital for availing all facilities like food management, vaccinations, ultrasonography from $1^{\text {st }}$ trimester to $3^{\text {rd }}$ trimester and support for special health care and also antenatal care for pregnancy period.

\section{Conclusion}

The findings of the study, ensuring to maintain the routine works of pregnant women for antenatal visit and identify the health care and also warning sign symptoms. Results of the survey shows more careful of maternal health care of target patients in developed countries through ANC visits. Due to uneducated and lacking of maternal health care awareness are resulted the increasing trends of mortality rate of pregnant women in Bangladesh. Moreover, as a developing country, Bangladesh has been trying to improve the antenatal care, and reduce the maternal mortality rate. The government of Bangladesh has been working on the antenatal care in both urban and rural areas. For fulfilling the sustainable goal and to make sure the bright future of our nation at first, we should work for mother health or Antenatal Care.

\section{Acknowledgments}

None.

\section{Conflicts of interest}

Author declare that there is no conflict of interest.

\section{Funding}

None. 


\section{References}

1. World Health Organization. WHO recommendations on antenatal care for a positive pregnancy experience: World Health Organization 2016.

2. Bellal Hossain TS. Nutritional status of pregnant women in selected rural and urban area of Bangladesh. Journal of Nutrition \& Food Sciences. 2018 .

3. Reduction of maternal mortality: a joint WHO/UNFPA/UNICEF/World Bank statement. Geneva, World Health Organization. 1999.

4. Revised 1990 Estimates of Maternal Mortality: A New Approach by WHO and UNICEF. World Health Organization, Geneva; 1996.

5. The Progress of Nations. UNICEF, New York; 1996.

6. Prual A, Toure A, Huguet D, et al. The quality of risk factor screening during antenatal consultations in Niger. Health Policy Planning. 2000;15(1):11-16.

7. World Health Organization (WHO). WHO recommended interventions for improving maternal and new-born health. Geneva: WHO Department of Making Pregnancy Safer. 2009.

8. Alkema L, Chou D, Hogan D, et al. Global, regional, and national levels and trends in maternal mortality between 1990 and 2015, with scenariobased projections to 2030: a systematic analysis by the UN Maternal Mortality Estimation Inter-Agency Group. Lancet. 2016;387(10017):462474.

9. World Health Organization. maternal mortality. Fact sheet; Geneva; 2018

10. Blencowe H, Cousens S, Jassir F, et al. National, regional, and worldwide estimates of stillbirth rates in 2015, with trends from 2000: a systematic analysis. Lancet. 2016;4(2):e98-108.

11. World Health Organization (WHO). Mother-baby package: implementing safe motherhood in countries: practical guide, WHO/FHE/MSM?94.11 Rev.1. Geneva; 1996.

12. World Health Organization (WHO). WHO global database on maternal health indicators. 2017.
13. World Health Organization. WHO recommendations on antenatal care for a positive pregnancy experience. Geneva, Switzerland; 2016.

14. Chowdhury RI, Islam MA, Gulshan J, et al. Delivery complications and healthcare-seeking behavior: the Bangladesh Demographic Health Survey, 1999-2000. Health and Social Care in the Community. 2007:15(3):254 264.

15. Koenig MA, Jamil K, Streatfield PK, et al. Maternal health and careseeking behavior in Bangladesh: Findings from a national survey. International Family Planning Perspectives. 2007;33(2):75-82.

16. Amin R, Shah NM, Stan Becker S. Socioeconomic factors differentiating maternal and child health-seeking behavior in rural Bangladesh: A crosssectional analysis. International Journal for Equity in Health. 2010;9:9.

17. Islam MM, Masud MS. Health care seeking behavior during pregnancy, delivery and the postnatal period in Bangladesh: Assessing the compliance with WHO recommendations. Midwifery. 2018;63:8-16.

18. National Institute of Population Research and Training (NIPORT), Mitra and Associates. ICF International. Bangladesh Demographic and Health Survey. 2011.

19. National Institute of Population Research and Training, Measures Evaluation, University of North Carolina at Chapel Hill, icddr b. Bangladesh Maternal Mortality and Health Care Survey 2010. 2012.

20. National Institute of Population Research and Training (NIPORT, Associates for Community and Population Research (ACPR), ICF International. Bangladesh Health Facility Survey 2014. Dhaka, Bangladesh; 2016

21. UNICEF. Multiple Indicator Cluster Survey. 2018.

22. Vyas S, Kumaranayake L. Constructing socio-economic status indices: how to use principal components analysis. Health policy and planning. 2006;21(6):459-468.

23. Wold S, Esbensen K, Geladi P. Principal component analysis. Chemometrics and intelligent laboratory systems. 1987;2(1-3):37-52. 